\title{
Effect of Interpregnancy Interval on Postpartum Maternal Anthropometry in Owerri, Nigeria
}

\author{
Iheukwumere $\mathrm{CB}^{1}$, Wariso $\mathrm{CA}^{1}$, Onyegbule $\mathrm{AO}^{2}$, Njoku $\mathrm{T}^{2}$, \\ Ejiobi $\mathrm{BC}^{3}$, Egwu OA ${ }^{3}$. \\ ${ }^{1}$ Department of Physiology, College of Medicine and Health Sciences, Abia State University, Uturu, Nigeria. \\ ${ }^{2}$ Department of Obstetrics and Gynaecology, Federal Medical Center, Owerri, Imo State, Nigeria. \\ ${ }^{3}$ Department of Anatomy, Faculty of Basic Medical Sciences, Federal University Ndufu-Alike Ikwo Ebonyi State, Nigeria.
}

\begin{abstract}
Summary
Background: Pregnancy weight gain and retention of gained weight following delivery is of great concern as regards to maternal obesity and its associated health risks. The influence of the length of inter-pregnancy interval on maternal weight outcomes, following delivery, is unknown.
\end{abstract}

Aim: The prospective study aims to investigate the effect of inter-pregnancy interval on postpartum weight loss in Nigerian women.

Subjects and Methods: A total of 80 pregnant women in labour were recruited based on a set criteria and anthropometric measurements were taken within 24 hours of delivery then repeated 6 weeks after. Mothers were grouped under the following inter-pregnancy interval (IPI) groups: IPI of more than 1 year to 2 years $(>1 \leq 2)$, IPI of 1 year or less $(\leq 1)$ and IPI of more than 2 years $(>2)$. Data analysis and entry were done using SPSS viewer (13), with $P$ value $\leq 0.05$ considered as significant.

Results: Though we recorded reductions in maternal weight $(M W)$, mid arm circumference (MAC), waist circumference (WC), mid-thigh circumference (MTC) and hip circumference (HC) only MTC was significant among the 3 groups with $P$ value 0.02 while MW, MAC, WC and HC had the following P values 0.07, 0.87, 0.96 and 0.48 respectively.

Conclusion: There is no significant effect of inter-pregnancy interval on postpartum maternal weight loss and as such its modification may not contribute to the prevention of obesity and its associated complications.

Keywords: Maternal anthropometry, inter-pregnancy interval, weight loss, Nigeria.

\section{Introduction}

Public health investigators have reported that the length of time between delivery and conception of the next pregnancy (inter-pregnancy interval or IPI) or birth of the next child (inter-birth interval) is associated with outcomes of the subsequent pregnancy ${ }^{1^{-4}}$. Research has shown that giving birth to two or more children in a short inter-pregnancy interval (defined as less than 12 months) appears to increase the risk of adverse perinatal infant outcomes and increased maternal morbidity and mortality ${ }^{5-10}$. Studies have been done to describe the association of high parity and obesity though largely inconclusive, some report that giving birth to one child compared to never having children appears to double the risk of major weight gain or obesity over a 5 year period $^{11^{-14}}$. A few studies have also reported a non-significant association between parity and obesity ${ }^{15-16}$, while other studies show that multiparous women having at least two or morechildren compared to primiparous or nulliparous women have the greater increase in obesity ${ }^{11}{ }^{17}{ }^{\prime}{ }_{18}$. The length of IPI among the multiparous groups in previous studies may be an important factor to consider hence, the inconsistencies in previous reports. The influence of IPI on maternal weight outcomes as regards to obesity, remain a debate. It is conceivable that short IPI may increase the risk of maternal obesity due to possible cumulative significant weight changes in between pregnancies due to pregnancy weight retention. A Swedish cohort study found that an inter-pregnancy weight gain of $1-2$ body mass index (BMI) units during an average of two years increases the risk of weight-related diseases, gestational hypertension and diabetes by $20-40 \% .{ }^{19}$ Another study found that multiparous women with short inter-pregnancy intervals, with or without excessive pregnancy weight gain, had a substantial risk of obesity after childbirth compared to multiparous women with longer inter-pregnancy intervals ${ }^{20}$, this is consistent with a previous study by Zhu and colleagues suggesting an inter-pregnancy interval of $18-23$ months may be optimal for preventing adverse maternal and infant health outcomes. ${ }^{7}$ Present study attempts to evaluate the effect of inter-pregnancy as a possible factor affecting the extent of pregnancy-weight lost within six weeks of delivery thus contributing to a reduction in pregnancy weight retention and risk of obesity. 


\section{Subjects And Methods}

Study design: This was a survey study conducted in Federal Medical Center Owerri (F.M.C.O), Imo State of Nigeria. Eighty (80) participants were recruited at the labour ward, duly counseled and written informed consent obtained. The study protocol and consent form were approved by the ethical and research committee of Federal Medical Center Owerri. At presentation, the antenatal care cards are retrieved, reviewed and relevant information such as age, parity, inter-pregnancy interval and birth plan as earlier discussed by the care giver. However, the primary outcomes were maternal weight, mid arm, waist, hip and mid-thigh circumference all measured 24 hours after delivery and during the six weeks postpartum visit.

\section{Eligibility and Exclusion Criteria}

To be eligible, a participant had to be pregnant, at least 18 years of age, completed secondary school education and in third trimester. They had to be non-smokers, and not on any medications which could affect their body composition such as steroids. They most also have abstained from alcohol during the period of pregnancy. Exclusion criteria also included medical or obstetric complications during pregnancy and delivery such as hypertension, pre-eclampsia, eclampsia, sickle cell disease, tuberculosis, gestational diabetes etc. Participant must have had a successful vaginal delivery and an activity score of $<3.0$ according to the 2005 Dietary Guidelines for Americans by the United states Department of Agriculture.

\section{Study Implementation and Questionnaires}

All interviews and measurements took place in the Federal Medical Center Owerri. During the six weeks post natal visit, interviews were conducted using both close and open-ended questionnaires to collect information on health history and physical activity- the type of exercise, its intensity and frequency. Physical activity level was assessed based on the recommendations of the 2005 Dietary Guidelines for Americans by the United States Department of Agriculture. A score of physical activity was derived by multiplying the number of days one exercised within one week by duration of the activity. For example, a participant who exercised 15 minutes a day, 4 times a week would have an activity score of 1 (4 x 0.25$)$. Sedentary or inactive was defined as having an activity score of $0-1.4$, moderately active was $1.5-2.9$ and very active > $3.0^{21}$.

\section{Body Composition Measurements}

Body composition measurements were conducted 24 hours of delivery and during the 6 weeks postnatal visit. Each participant's weight was measured wearing minimal clothing and without shoes or jewelry on the body. Weight was measured to the nearest $0.1 \mathrm{Kg}$ with heightometerRGZ-120 Health scale which is a calibrated weighing scale. The mid arm, mid-thigh, hip and waist circumferences were measured with a butterfly brand measuring tape to the nearest $0.1 \mathrm{~cm}$ at delivery and at six weeks postpartum.

\section{Statistical Analysis}

Data entry and analysis were done using SPSS viewer (13.0). Descriptive statistics such as percentages, mean, standard deviation (SD) and range were used for data analysis. Data are reported as mean \pm SD. Multiple regression analysis was used for analysis. $\mathrm{P}$ value of 0.05 was used as a criterion for reporting statistical significance.

\section{Sample Size and Categories:}

\section{Results}

Forty seven (47) mothers completed the six weeks postpartum follow-up. Out of the 80 recruited for the study, 33 were lost to follow up. $23.4 \%$ fell into $>1 \leq 2$ IPI group, $46.8 \%$ of the participants correspond to $\leq 1$ IPI group while $29.8 \%$ were of the $>2$ IPI group.

\section{Anthropometric Changes:}

$\leq 1$ IPI group recorded the highest average weight loss of $6.9 \mathrm{~kg}$ followed by $>1 \leq 2$ IPI group with average of $5 \mathrm{~kg}$ and lastly $>2$ IPI group with an average of $4.4 \mathrm{~kg}$. There was no significant difference in weight loss among the three groups $(\mathrm{P}=0.07)$. Average changes in WC of IPI groups $>1 \leq 2, \leq 1$ and $>2$ were $1.3 \mathrm{~cm}$, $1.2 \mathrm{~cm}, 1.3 \mathrm{~cm}$ respectively which showed no significant difference among the groups $(\mathrm{P}=0.96$. Average change in $\mathrm{HC}$ of the various IPI groups; $>1 \leq 2, \leq 1$ and $>2$ were $1.5 \mathrm{~cm}, 2.5 \mathrm{~cm}$ and $1.5 \mathrm{~cm}$ respectively giving no significant difference among the three groups $(\mathrm{P}=0.48)$. The average change in MAC for groups; $>1 \leq 2, \leq 1$ and $>2$ were $1.1 \mathrm{~cm}, 1.3 \mathrm{~cm}$ and $1.5 \mathrm{~cm}$ respectively also showed no significant difference $(\mathrm{P}=0.87)$. However, changes in the average MTC between the three groups were significant with groups; $>1 \leq 2, \leq 1$ and $>2$ having $1.7 \mathrm{~cm}, 1 \mathrm{~cm}$ and $1 \mathrm{~cm}$ reductions respectively $(\mathrm{P}=0.02)$.

\section{Discussions}

Present study has shown that inter-pregnancy interval has no dependent effect on post-partum weight reduction and may not be a helpful guide in attempt at reducing weight gained during pregnancy. The loss of 
$41 \%$ of the recruited women to postnatal care follow up is rather worrisome considering the level of sensitization given to them during antenatal care on the relevance of postnatal care. Although earlier reports show that only about $36 \%$ of women in Nigeria attend postnatal care ${ }^{22}$. The possibility of lack of confidence in government owned health facilities owing to the incessant industrial actions by health care professionals may be a possible contributor to this loss in follow up as some may seek postnatal care in private health establishments. Weight gained in pregnancy is largely attributed to the anabolic effect of placental hormones which tend to decline following delivery of placenta during childbirth. The decline in placental hormoneswhich may be responsible for the postpartum reductions in anthropometric measurements noted in the study, were duly expected.This explains the increased risk of obesity among women with short inter-pregnancy interval as noted by Esa $\mathrm{M}$ et $\mathrm{al}^{20}$, where a relatively short time is required for the circulating placental hormones to wane off thus the persistence or lingering of their anabolic effects even in the early postpartum period. The selective significant anthropometric change noted in the Mid-thigh circumference may be as a result of the large muscle tissue bulk around the thighs serving as a potential site for anabolic build up by the circulating placental hormones during pregnancy. Possibilities of increased tissue receptors for these hormones around the region of the thigh cannot be ruled out and may be pointer for further research. The increased risk of obesity attributed to a short inter-pregnancy interval ( $<12$ months) may be as a result of a superimposition of unshed weight gained in previous pregnancy by new weight-gain in subsequent pregnancy and has no direct effect on the rate of weight that is shed in the postpartum period.

\section{Limitation of Study}

The large percentage of the participants that were lost to follow up unavoidably reduced the sample size in the study. A similar study with a larger sample size may be carried out and results compared with the present study.

\section{References}

[1]. Hughes E. Children's Bureau Publication. US Children's Bureau; Washington, DC: 1923. Infant Mortality: Results of a Field Study in Gary, Indiana, Based on Births in One Year; p. 112.

[2]. Woodbury R. Children's Bureau Publication. US Children's Bureau; Washington, DC: 1925. Causal Factors in Infant Mortality: a Statistical Study Based on Investigations in Eight Cities; p. 112.

[3]. Eastman NJ. The effect of the interval between births on maternal and fetal outlook. American Journal of Obstetrics and Gynecology. 1944;47:445-466.

[4]. Yerushalmy J. On the interval between successive births and its effect on the survival of the infant - I. An indirect method of study. Human Biology. 1945;17:65-106.

[5]. Conde-Agudelo A, Belizan JM. Maternal morbidity and mortality associated with interpregnancy interval: cross sectional study. Bmj. 2000;321:1255-9. [PMC free article][PubMed]

[6]. Conde-Agudelo A, Rosas-Bermudez A, Kafury-Goeta AC. Effects of birth spacing on maternal health: a systematic review. Am J Obstet Gynecol. 2007;196:297-308. [PubMed]

[7]. Zhu BP, Haines KM, Le T, McGrath-Miller K, Boulton ML. Effect of the interval between pregnancies on perinatal outcomes among white and black women. Am J Obstet Gynecol.2001;185:1403-10. [PubMed]

[8]. Grisaru-Granovsky S, Gordon ES, Haklai Z, Samueloff A, Schimmel MM. Effect of interpregnancy interval on adverse perinatal outcomes--a national study. Contraception.2009;80:512-8. [PubMed]

[9]. Rodrigues T, Barros H. Short interpregnancy interval and risk of spontaneous preterm delivery. Eur J ObstetGynecolReprod Biol. 2008;136:184-8. [PubMed]

[10]. Zhu BP. Effect of interpregnancy interval on birth outcomes: findings from three recent US studies. Int $\mathrm{J}$ Gynaecol Obstet. 2005;89 (Suppl 1):S25-33. [PubMed]

[11]. Gunderson EP, Quesenberry CP, Jr, Lewis CE, et al. Development of overweight associated with childbearing depends on smoking habit: The Coronary Artery Risk Development in Young Adults (CARDIA) Study. Obes Res. 2004;12:2041-53. [PMC free article] [PubMed]

[12]. Davis EM, Zyzanski SJ, Olson CM, Stange KC, Horwitz RI. Racial, ethnic, and socioeconomic differences in the incidence of obesity related to childbirth. Am J Public Health.2009;99:294-9. [PMC free article] [PubMed]

[13]. Williamson DF, Madans J, Pamuk E, Flegal KM, Kendrick JS, Serdula MK. A prospective study of childbearing and 10-year weight gain in US white women 25 to 45 years of age. Int J ObesRelatMetabDisord. 1994;18:561-9. [PubMed]

[14]. Rosenberg L, Palmer JR, Wise LA, Horton NJ, Kumanyika SK, Adams-Campbell LL. A prospective study of the effect of childbearing on weight gain in African-American women. Obes Res. 2003;11:1526-35. [PubMed

[15]. Brown JE, Kaye SA, Folsom AR. Parity-related weight change in women. Int J ObesRelatMetabDisord. 1992;16:627-31. [PubMed]

[16]. Heliovaara M, Aromaa A. Parity and obesity. J Epidemiol Community Health. 1981;35:197-9. [PMC free article] [PubMed]

[17]. Coitinho DC, Sichieri R, D'AquinoBenicio MH. Obesity and weight change related to parity and breast-feeding among parous women in Brazil. Public Health Nutr. 2001;4:865-70.[PubMed]

[18]. Magann EF, Doherty DA, Chauhan SP, Klimpel JM, Huff SD, Morrison JC. Pregnancy, obesity, gestational weight gain, and parity as predictors of peripartum complications. Archives of gynecology and obstetrics. 2011;284:827-36. [PubMed]

[19]. Villamor E, Sparen P, Cnattingius S. Interpregnancy weight gain and the male-to-female sex ratio of the second pregnancy: a population-based cohort study. FertilSteril. 2008;89:1240-4.[PubMed]

[20]. 20.Esa M.D, Denis C. B, Xuelu, Stephen Z, Barbara A, Lisa B and Ralph H.Short inter-Pregnancy intervals, parity, excessive pregnancy weight gain and risk of maternal obesity: Matern. Child Health.J. 2014 Apr.18(3):554-562. Do: 10.1007/S10995-0131272-3

[21]. Ukegbu PO, UwaegbuteA C. Body Composition changes among lactating mother in Abia state, Nigeria. American journal of food ad nutrition 2012, 2(1):21-25.

[22]. National Population commission (NPC) and ICF Macro. 2009. Nigeria Demographic and Health survey 2008: key findings. Calverton, Maryland, USA: NPC and ICF macro. Available from: http://dusprogram. Com/pubs/pdf/Sr 173.pdf 